\title{
An in Vitro Evaluation of Pressure Generated by Programmed Intermittent Epidural Bolus (PIEB) or Continuous Epidural Infusion (CEI)
}

\author{
Silvia Stirparo ${ }^{1}$, Stefania Fortini ${ }^{2}$, Stefania Espa $^{2}$, Antonio Cenedese ${ }^{2}$, Giorgio Capogna ${ }^{1}$ \\ ${ }^{1}$ Department of Anesthesiology, Città di Roma Hospital, Rome, Italy; ${ }^{2}$ DICEA Dipartimento di Ingegneria Civile, Edile e Ambientale, \\ La Sapienza University, Rome, Italy. \\ Email: silvia.stirparo@yahoo.it
}

Received March 11 ${ }^{\text {th }}, 2013$; revised April 20 $0^{\text {th }}, 2012$; accepted May 10 ${ }^{\text {th }}, 2013$

Copyright (C) 2013 Silvia Stirparo et al. This is an open access article distributed under the Creative Commons Attribution License, which permits unrestricted use, distribution, and reproduction in any medium, provided the original work is properly cited.

\begin{abstract}
PIEB has been reported as being superior to CEI for labor analgesia. The aim of this study was to measure the pressures generated by two commercially available pumps (CADD PIB, Smiths and Gemstar, Hospira) when delivering PIEB or CEI at 2 commonly used rates of infusion $(10$ or $5 \mathrm{~mL}$ ). The two pumps were set to deliver fluid at four rates (CEI: 5 or $10 \mathrm{~mL} / \mathrm{h}$; PIEB: 5 or $10 \mathrm{~mL}$ every h) and connected to a pressure transducer (PCB Piezotronics 1500 connected to a NI USB-6251 Screw Terminal) to determine the pressures applied during each infusion. The peak pressure generated during the PIEB mode was consistently higher when compared to the CEI mode in both pumps. When comparing the two pumps in the PIEB $10 \mathrm{~mL}$ every hour mode, the peak pressures were approximately the same, while the pressure pattern differed. For each cycle the pressure generated by Gemstar oscillated from $25 \mathrm{mmHg}$ to $0 \mathrm{mmHg}$; whereas with the CADD pump the baseline pressure was above 0 . The Gemstar pump piston frequency $(1.2 \mathrm{~Hz})$ was twice as high as the CADD $(0.5 \mathrm{~Hz})$, so the volume delivered per cycle was lower. In the PIEB $5 \mathrm{~mL}$ every hour mode the peak pressures followed the same wave patterns. However, unlike the $10 \mathrm{~mL}$ mode, the pump piston frequency was approximately the same in both pumps. In both the CEI 5 or $10 \mathrm{~mL} / \mathrm{h}$ modes, the CADD peak pressure was four times greater than the Gemstar. Both cycled between their respective peak pressures and $0 \mathrm{mmHg}$. Since the peak pressure of the CADD was approximately the same with PIEB and CEI, we speculated that the most important factor affecting the distribution of the solution in the epidural space was not the peak pressure per se, but the mode of delivery of the bolus.
\end{abstract}

Keywords: Labor Analgesia; Epidural

\section{Introduction}

Recently, the technique of intermittent epidural bolus for labor analgesia administered by automated pumps (PIEB, programmed intermittent epidural bolus) has been introduced in alternative to the standard Continuous Epidural Infusion (CEI) technique to maintain labor analgesia [1-3].

As with CEI, intermittent boluses given by PIEB avoid the wide swings in the efficacy of analgesia commonly observed with manually administered boluses. However, in contrast to CEI, PIEB also reduces the total anesthetic dose consumption, decreases physician intervention, improves the quality of analgesia and maternal satisfaction, reduces the incidence of motor block and the likelihood of instrumental delivery [1-3].

It has been postulated that intermittent bolus through the epidural catheter has a wider and more uniform spread [4], most likely due to a higher injection pressure, which probably contributes to a better quality of block in the clinical setting.

The aim of this study was to measure the pressures generated by the epidural pump set in the PIEB or CEI mode, at two commonly used rates of infusion (10 or 5 $\mathrm{mL}$ ). For the purpose of the study, we compared the only two commercially available pumps capable of delivering both PIEB and CEI (CADD PIB, Smiths and Gemstar, Hospira).

\section{Material and Method}

The CADD (linear peristaltic) pump delivers fluid by the intermittent compression of a segment of silicone infusion tubing. The synchronised movement of two vertical 
bars controls the entry and release of fluid from this segment of tubing. Fluid is only released when the tubing is compressed by the expulsor and thus a significant driving pressure is produced.

In the Gemstar volumetric piston pump a pumping chamber interfaces with a piston in the infuser: when the piston is depressed, fluid in the chamber is exhausted through a one-way outlet valve to a small outlet chamber. When the piston is retracted, the outlet valve closes and a one-way inlet valve opens to let fluid in from a small inlet chamber.

The catheter used in this study was the Portex $16 \mathrm{G}$ with 3 lateral holes in the distal $15 \mathrm{~mm}$ segment.

The two pumps being tested were set to deliver $0.0625 \%$ levobupivacaine at four rates CEI: 5 or $10 \mathrm{~mL} / \mathrm{h}$; PIEB: 5 every h or $10 \mathrm{~mL}$ every $\mathrm{h}$.

The system was linked to a pressure transducer (PCB Piezotronics 1500 connected to a NI USB-6251 Screw Terminal) to determine the pressures applied to the epidural catheter during each infusion, and the pressures were displayed on a monitor and recorded by a computer.

All conditions were repeated in triplicate. The maximum pressure measurable was $375 \mathrm{mmHg}$.

Please do not revise any of the current designations.

\section{Results}

Pressure waveforms produced by each pump are shown in the Figures 1-8 and the peak pressures created at each rate are reported in Tables $\mathbf{1}$ and $\mathbf{2}$.

There was a difference of $0.02 \%$ between the measures obtained in triplicate and therefore data are presented as mean with no SD.

Table 1. Peak pressures $(\mathrm{mmHg})$ generated during PIEB mode, at different infusion rates.

\begin{tabular}{cccc}
\hline Pump & $\begin{array}{c}\text { PIEB bolus per } \\
\text { hour }[\mathrm{mL}]\end{array}$ & $\begin{array}{c}\text { Peak Pressure } \\
{[\mathrm{mmHg}]}\end{array}$ & $\begin{array}{c}\text { Frequency } \\
\text { Wave }[\mathrm{Hz}]\end{array}$ \\
\hline \multirow{2}{*}{ GEMSTAR } & 10 & 25.0 & 1.2 \\
& 5 & 15.1 & 0.5 \\
\multirow{2}{*}{ CADD } & 10 & 26.7 & 0.5 \\
& 5 & 25.2 & 0.4 \\
\hline
\end{tabular}

Table 2. Peak pressures (mmHg) generated during CEI mode, at different infusion rates.

\begin{tabular}{cccc}
\hline Pump & $\begin{array}{c}\text { CEI Infusion } \\
\text { Rate }[\mathrm{mL} / \mathrm{h}]\end{array}$ & $\begin{array}{c}\text { Peak Pressure } \\
{[\mathrm{mmHg}]}\end{array}$ & $\begin{array}{c}\text { Frequency } \\
\text { Wave }[\mathrm{Hz}]\end{array}$ \\
\hline \multirow{2}{*}{ GEMSTAR } & 10 & 6.2 & 0.3 \\
& 5 & 5.8 & 0.15 \\
\multirow{2}{*}{ CADD } & 10 & 23.2 & 0.05 \\
& 5 & 23.3 & 0.025 \\
\hline
\end{tabular}

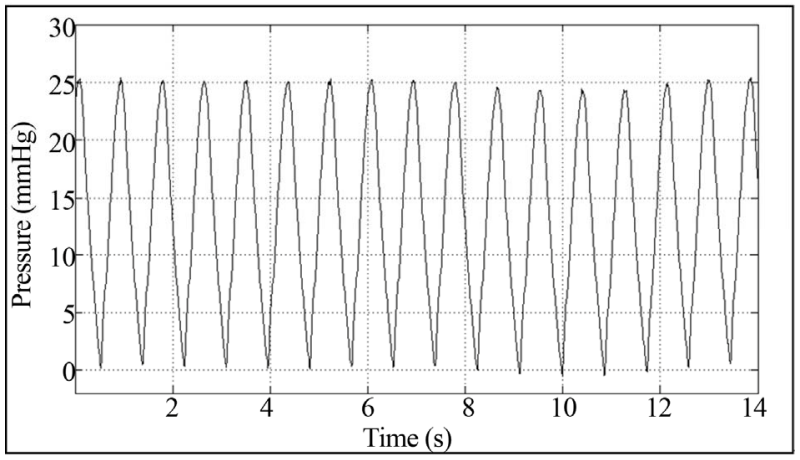

Figure 1. Pressure waveforms produced by the Gemstar pump in PIEB $10 \mathrm{~mL}$ every hour mode.

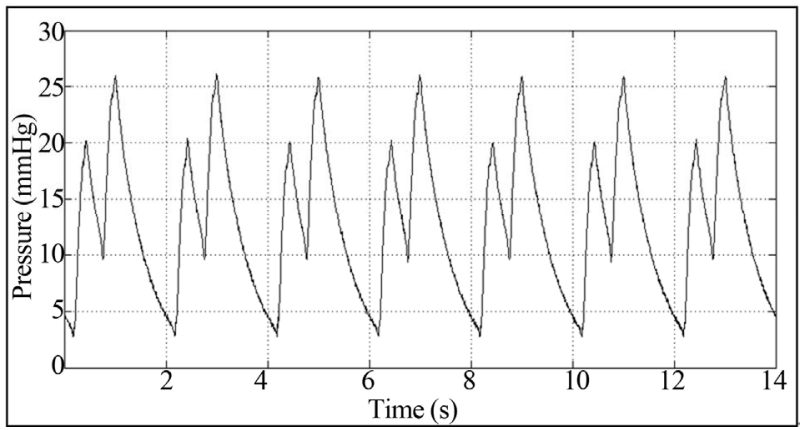

Figure 2. Pressure waveforms produced by the CADD pump in PIEB $10 \mathrm{~mL}$ every hour mode.

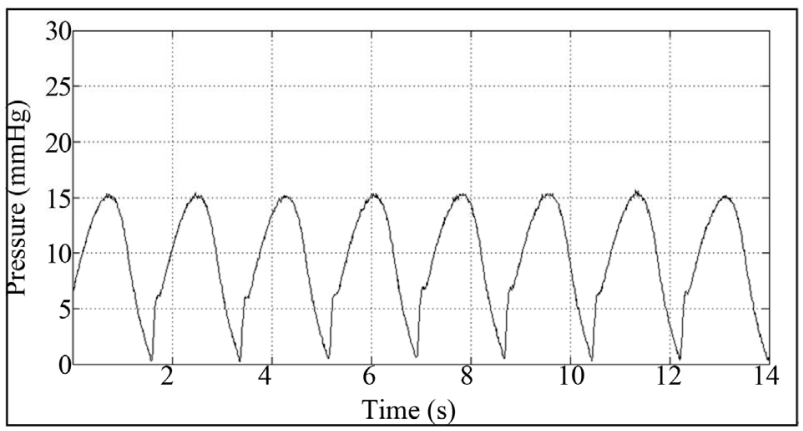

Figure 3. Pressure waveforms produced by the Gemstar pump in PIEB $5 \mathrm{~mL}$ every hour mode.

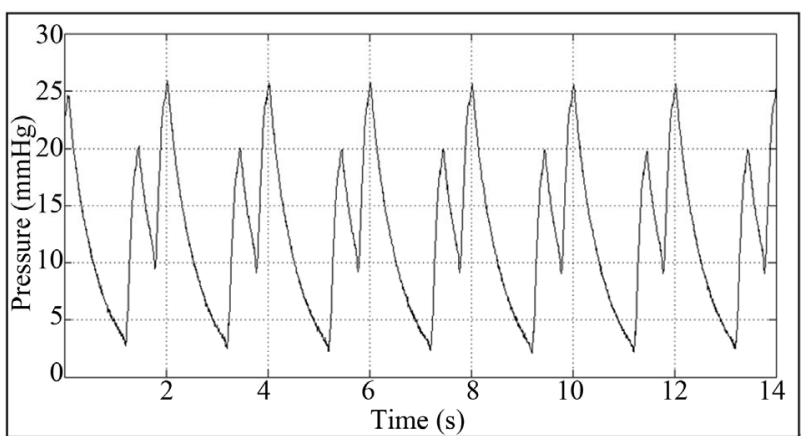

Figure 4. Pressure waveforms produced by the CADD pump in PIEB $5 \mathrm{~mL}$ every hour mode. 


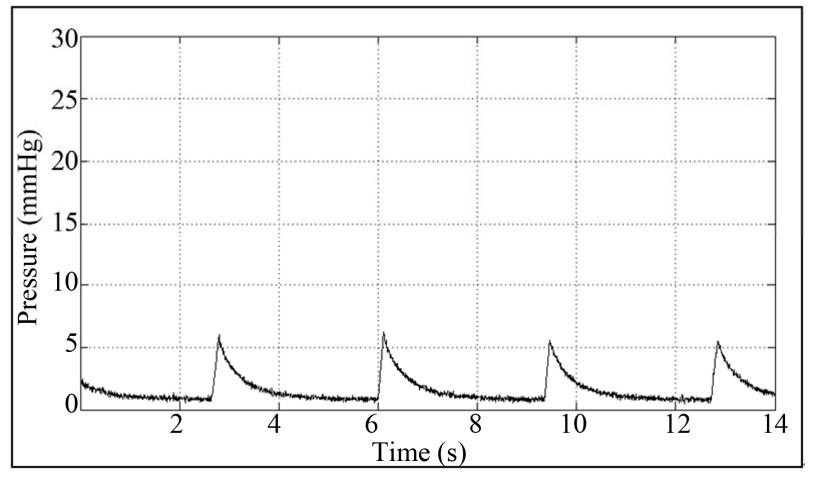

Figure 5. Pressure waveforms produced by the Gemstar pump in CEI $10 \mathrm{~mL} / \mathrm{h}$ mode.

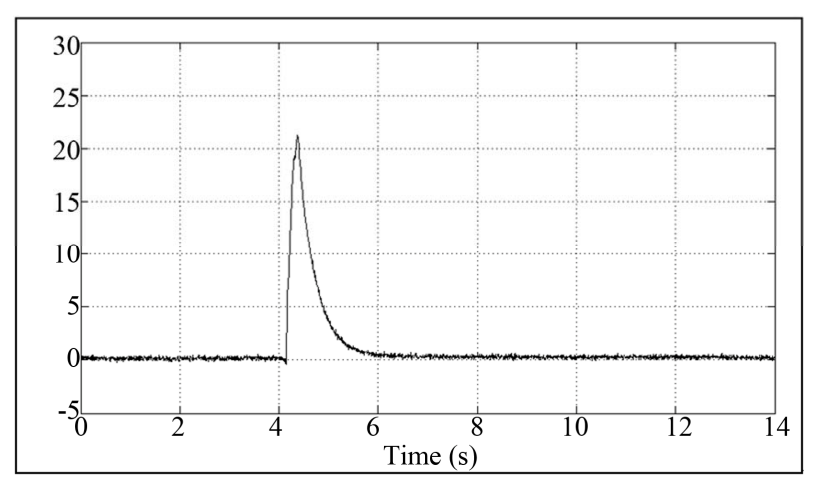

Figure 6. Pressure waveforms produced by the CADD pump in CEI $10 \mathrm{~mL} / \mathrm{h}$ mode.

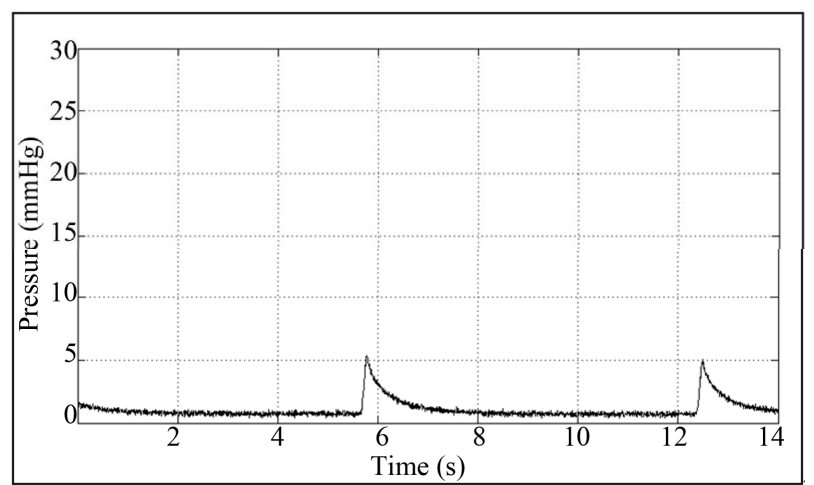

Figure 7. Pressure waveforms produced by the Gemstar pump in CEI $5 \mathrm{~mL} / \mathrm{h}$ mode.

In the PIEB $10 \mathrm{~mL}$ every hour mode, the peak pressures generated by both pumps were approximately the same, however the pressure pattern of the two pumps differed.

For each cycle the pressure generated by Gemstar oscillated from the peak $(25 \mathrm{mmHg})$ to the baseline $(0$ $\mathrm{mmHg}$ ) whereas the CADD pump generated a biphasic wave, which maintained the baseline pressure above 0 .

The Gemstar pump piston frequency $(1.2 \mathrm{~Hz})$ was more or less twice as high as the CADD $(0.5 \mathrm{~Hz})$, so the

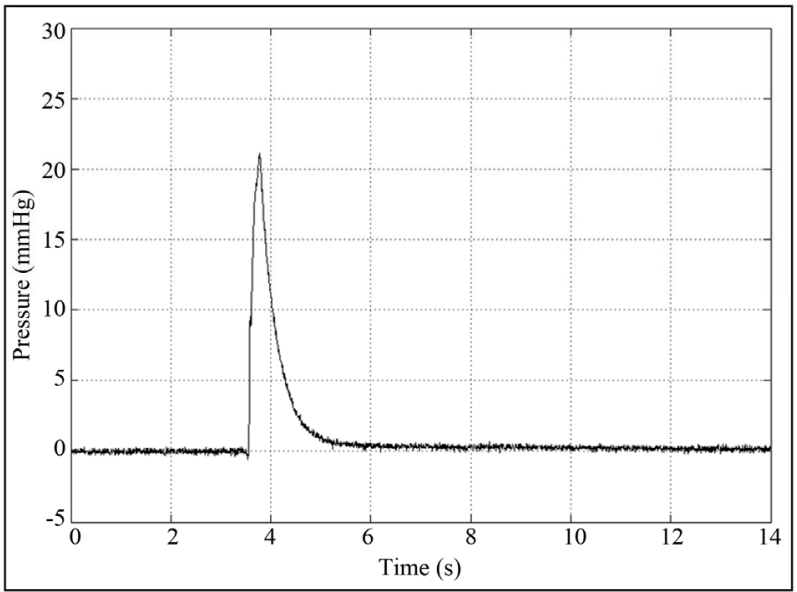

Figure 8. Pressure waveforms produced by the CADD pump in CEI $5 \mathrm{~mL} / \mathrm{h}$ mode.

volume delivered per cycle was lower. Therefore the Gemstar pump delivered the same programmed volume in a series of small, frequent boluses while the CADD pump delivered it in a series of larger, slower boluses.

In the PIEB $5 \mathrm{~mL}$ every hour mode the peak pressures were lower as compared to the $10 \mathrm{~mL}$ mode but followed the same wave patterns when the Gemstar was compared to the CADD. However, unlike the $10 \mathrm{~mL}$ mode, the pump piston frequency was approximately the same in both models.

In both the CEI 5 or $10 \mathrm{~mL} / \mathrm{h}$ modes, the peak pressures generated by the two pumps were completely different, in that the CADD peak pressure was four times greater than the Gemstar. Both cycled between their respective peak pressures and $0 \mathrm{mmHg}$.

The Gemstar pump piston frequency was six times higher than the CADD, so again the volume delivered per cycle was lower.

\section{Discussion}

It is believed that the reason for the analgesic success of intermittent boluses when compared to continuous administration may be that solutions injected into the epidural space tend to spread more uniformly when injected as a bolus, as compared to a continuous infusion $[4,5]$.

The results of our study support the hypothesis that the greater diffusion of the local anesthetic solution in the epidural space may be due to higher pressure generated by the PIEB technique when compared with the CEI technique. Infact we observed that the peak pressure generated during the PIEB mode at different infusion rate was consistently higher when compared to the CEI mode, in all measurements, in both pumps.

However, since the peak pressure of the CADD pump was approximately the same with PIEB and CEI, we also 
speculate that the most important factor influencing the greater spread of the epidural solution may be not the peak pressure per se, but the mode of delivery of the bolus which may affect, in turn, the dynamics of nerve block [6].

It is "technically impossible" with a peristaltic pump to deliver a real single bolus and a real continuous infusion because of the nature of the pump since the pistons generate a predefined pressure on the infusion line at a predefined frequency according to the mode setting. Yet, according to the results of our study the CADD pump system simulates a "true" PIEB as well as a "true" CEI mode much more closely than the Gemstar.

In conclusion, our findings suggest that not only the pump injection pressure but also the intermittent nature of mode of delivery of the bolus play an important role in determining the distribution of the epidural solution.

\section{REFERENCES}

[1] C. Wong, J. T. Ratliff, J. T. Sullivan, B. Scavone, P. Toledo and R. J. McCarthy, "A Randomized Comparison of Programmed Intermittent Epidural Bolus with Continuous Epidural Infusion for Labor Analgesia," Anesthesia \& Analgesiag, Vol. 102, No. 3, 2006, pp. 904-909.

\section{doi:10.1213/01.ane.0000197778.57615.1a}

[2] G. Capogna, M. Camorcia, S. Stirparo and A. Farcomeni, "Programmed Intermittent Epidural Bolus versus Continuous Epidural Infusion for Labor Analgesia: The Effects on Maternal Motor Function and Labor Outcome. A Randomized Double-Blind Study in Nulliparous Women," Anesthesia \& Analgesiag, Vol. 113, No. 4, 2011, pp. 826831.

[3] C. A. Wong, R. J. McCarthy and B. Hewlett, "The Effect of Manipulation of the Programmed Intermittent Bolus Time Interval and Injection Volume on Total Drug Use for Labor Epidural Analgesia: A Randomized Controlled trial," Anesthesia \& Analgesiag, Vol. 112, No. 2, 2011, pp. 904-911. doi:10.1213/ANE.0b013e31820e7c2f

[4] A. M. Kaynar and K. B. Shankar, "Epidural Infusion: Continuous or Bolus?" Anesthesia \& Analgesiag, Vol. 89, No. 2, 1999, p. 534.

[5] Q. Hogan, "Distribution of Solution in the Epidural Space: Examination by Cryomicrotome Section," Regional Anesthesia and Pain Medicine, Vol. 27, No. 2, 2002, pp. 150-156.

[6] R. H. De Jong, "Dynamics of Nerve Block," In: R. H. De Jong, Ed., Local Anesthetics, Mosby, St Louis, 1994, pp. 230-245. 